\title{
Effect of genotype and sex on fiber growth rate of alpacas for their first year of fleece production
}

\author{
Efecto del genotipo y sexo sobre la tasa de crecimiento de la fibra de alpacas durante el \\ primer año de producción de vellón
}

\author{
EC Quispe-Peña ${ }^{a^{*}}$, AG Poma-Gutiérrez ${ }^{\mathrm{a}}$, BA McGregor ${ }^{\mathrm{b}}$ and J Bartolomé-Filella ${ }^{\mathrm{c}}$ \\ ${ }^{a}$ Veterinary Medicine and Husbandry Department. National University of Micaela Bastidas de Apurimac, Abancay, Peru. \\ 'Institute of Frontier Materials, Deakin University, Geelong, Australia. \\ 'Department of Animal and Food Science, Ruminant Research Group, Universitat Autònoma de Barcelona, Spain.
}

\begin{abstract}
RESUMEN
La venta de la fibra de alpaca constituye el principal ingreso económico para miles de familias que viven en la zona altoandina de Perú. Por otro lado, la fibra que crece durante el primer año de vida de los animales resulta ser la más valorada, sin embargo en la actualidad, existe muy poca información acerca de la tasa de crecimiento de la fibra (TCF) durante este periodo. Por estas consideraciones en la zona altoandina de Perú (Huancavelica) se realizó el presente trabajo a fin de determinar la TCF, para lo cual se utilizaron 22 crías de alpacas de dos genotipos (10 Suri, 12 Huacaya) considerando diferencias entre sexos (10 hembras, 12 machos). La técnica del "teñido de banda" fue utilizada para determinar la TCF. Para evaluar el efecto del sexo, mes y genotipo se utilizó un modelo aditivo lineal de efectos principales. Adicionalmente para evaluar el efecto del sexo y genotipo sobre la TCF a lo largo del año se utilizó un modelo de medidas repetidas con dos factores: genotipo y sexo. Los resultados mostraron que la TCF es afectada por el genotipo y el mes pero no por el sexo. De este modo la fibra de Alpacas Suri crece un $20 \%$ más que fibras de alpacas Huacaya $(1,34$ contra $1,10 \mathrm{~cm} / \mathrm{mes}, \mathrm{P}<0,001)$. Asimismo se encontró que la TCF se incrementa significativamente durante los primeros tres meses $(\mathrm{P}<0,05)$, pero que luego se mantiene casa constante. En función a la TCF, se concluye que es posible la esquila de animales desde los 8 meses de edad, pues dichas fibras tendrían el largo suficiente para el requerimiento del proceso textil.
\end{abstract}

Palabras clave: alpaca, longitud de fibra, tasa de crecimiento, esquila.

\section{SUMMARY}

The sale of alpaca fiber is the main income for thousands of families in the Central Andes of Peru. Little information exists on the fiber length growth rate of alpaca (FLG), especially throughout their first year of life when the fiber is most valuable. We aimed to determine the monthly FLG of 22 alpaca offspring of two genotypes (9 Suri, 13 Huacaya) and considering sex differences (10 females, 12 males) in the High Andes of Peru. FLG growth was determined using dye-bands. An additive lineal model with three factors (genotype, sex, month) was used for statistic analysis. To evaluate the effect of genotype and sex on the profile of the FLG throughout the year a two factor repeated-measures model was used. The results showed that FLG was affected by genotype and month but not sex. The Suri genotype had 20\% higher FLG than Huacaya genotype alpacas (1.34 vs $1.10 \mathrm{~cm} / \mathrm{month}$, $\mathrm{P}<0.001)$. FLG increased over each of the first three months $(\mathrm{P}<0.05)$ and then maintained a near constant rate for the remainder of the first year. The resulting staple length indicates that shearing at ages from 8 to 12 months of age will provide fleeces of sufficient length for textile processing.

Key words: alpaca, staple length, growth rate, shearing.

\section{INTRODUCTION}

Peru is the largest producer of alpaca fiber with annual production of around 3,500 MT and a national herd of around 3 million alpacas. The income of about 800,000 alpaca farmers depends mainly on the sale of fiber (Quispe et al 2009 ${ }^{\mathrm{b}}$ ). In Peru, farmers sell alpaca fiber according to the weight of the greasy fleece (GFW) and although buyers have recently been paying extra for

Accepted: 29.08.2013.

* Patibamba Baja s/n, Abancay, Peru; edgarquispe62@yahoo.com quality based on finer fiber, GFW is still more important regarding income (Quispe 2011).

Alpaca fiber has special features and the textile industry regards alpaca fiber as a specialty luxury fiber. Alpaca fiber is sought for its rarity, softness, range of natural colours and good strength (Watkins and Buxton 1992). The retail price for alpaca clothing such as jumpers for men can exceed US $\$ 500$ per piece.

Although the average fiber diameter (AFD) is the main determinant of quality (McGregor 2006), the staple length (SL) is a major determinant for the textile processing route of alpaca fiber (Wang et al 2003). The worsted system requires long fiber with good strength to 
withstand the stretching and tension during processing. The woolen processing system is capable of processing shorter fibers, some of which otherwise would be wasted (Carpio 1991). Worsted yarns are smoother, stronger, and more uniform and can be finer, thus giving the ultimate fabric a neat, smooth appearance. Worsted spun yarns are capable of producing the lightest fabrics which can show a visible structure that are of most value at the time of consumer purchase.

$\mathrm{SL}$ is a product of the fiber growth rate and the time between shearing. As shearing in alpacas is done at different intervals and in different months of the year there are different reports of alpaca SL (Solis 2000, Wuliji et al 2000, McGregor 2002, McGregor 2006, Lupton et al 2006, Quispe et al 2009a). Throughout the year there are variations in the quantity and quality of pastures, which affect the nutrition of alpacas as shown by gain and loss in live weight of alpacas (McGregor 2002). Thus it is likely that there are differences in the fiber length growth between months as observed with the variation of alpaca AFD (McGregor 2002, Poma et al 2009, Mayhua et al 2011). Moreover, as phenotype, which in our case is SL, is determined by genotype and the environment, it can also be expected that differences in SL exist between the two breeds of alpacas: Huacaya and Suri. Sohie (2003), McGregor and Butler (2004) and McGregor (2006) determined the effect of alpaca breed for variables such as AFD, SL, resistance to compression and staple strength, but did not evaluate fiber length growth rate (FLG) throughout the year.

Given the limited information available on FLG and the importance of SL in textile manufacturing, the purpose of this research was to determine the effects of factors such as sex, genotype and month of year on the FLG of young alpaca reared in the High Andes of Peru.

\section{MATERIAL AND METHODS}

\section{GENERAL}

The study was conducted at the Tucumachay site of the Research and Development Centre of South American Camelids, Lachocc, National University of Huancavelica, Peru. The site is located above $4443 \mathrm{~m}$. a.s.l. and $12^{\circ} 53^{\prime} 37^{\prime}$ ' $\mathrm{S} ; 7^{\circ} 05^{\prime} 25^{\prime \prime} \mathrm{W}$. The grazing is based on natural pastures composed mainly of Poaceae, Cyperaceae, Asteraceae and Juncaceae. Temperatures are typically: winter days, -5 to $0^{\circ} \mathrm{C}$; and summer days, 14 to $18^{\circ} \mathrm{C}$. Annual precipitation averages $750 \mathrm{~mm}$. At Tucumachay, 575 alpacas were raised in a grazing area of 530 ha, and 260 females alpacas gave birth between February and March in 2010. Average birth weight of cria was $7.2 \mathrm{~kg}$.

During the second week of March, 22 new born cria $($ males $=12$, females $=10 ;$ Suri $=9$, Huacaya $=13)$ were identified with ear tags. Immediately after birth each animal had an $8 \mathrm{~cm}^{2}$ patch identified on the mid-side area, centred over the $10^{\text {th }}$ rib and midway between the back line and belly line. The fiber was dye-banded each month for measuring the monthly FLG (Chapman and Wheeler, 1963). Thereafter, every 30 days throughout the year (April 2010 to April 2011) staple length of the non-dyed fiber was determined as the average length of 5 randomly measured staples using a metal millimetre ruler. Thus for each animal 12 sequential measurements were taken.

\section{STATISTICAL ANALYSIS}

The statistical analyses began with analysis to evaluate normal distribution, variance homogeneity and errors independence by Kolmogorov-Smirnov and Levenne tests. No data was removed. An additive lineal model with three factors (genotype, sex, month) and for comparison among genotypes, months and sex with terms accepted or rejected on the basis Bonferroni test $(\mathrm{P}<0.05)$ was used for statistic analysis. Also to evaluate the effect of genotype and sex on the profile of the FLG throughout the year a two factor repeated-measures model was used. To contrast multivariate effect (month) by genotype and by sex, Wilks's Lamba, Pillai's Traza and Hotelling's Traza statistics $(P<0.05)$ were used. Potential interactions between significant terms were tested but no interaction term was significant $(P>0.20)$. R V.2.13.1 software was used for all statistical analysis.

\section{RESULTS}

Sufficient evidence was obtained linked to differences due to genotype and month on FLG but not for differences due to sex.

The average, s.d., confidence intervals, lower and upper values of monthly FLG are given in table 1. FLG was significantly affected by alpaca genotype and the month of measurement $(\mathrm{P}<0.001$, table 1$)$. Suri alpaca had $20 \%$ higher FLG than Huacaya, and the differences in FLG profile resulted in differences in average SL between the breeds over the 12 month period amounting to (1.34-1.10 $\mathrm{cm} / \mathrm{month}$ ) $\hat{\mathrm{I}} 12=2.9 \mathrm{~cm}$. There was no evidence that sex affected FLG (table 1, figure 1).

FLG increased significantly during each of the first three months of life $(\mathrm{P}<0.05$, table 1 , figure 1$)$. For the remainder of the year, there was little difference in FLG between monthly measurements (table 1). These effects were detected for both breeds and sexes (figure 1). It is likely that the increase in FLG during the first three months of life is related to increases in voluntary feed intake and with increased live weight as the alpaca grow.

\section{DISCUSSION}

Similar differences in SL between Suri and Huacaya alpaca have been reported previously (Villarroel 1959, McGregor 2006). In one-year-old Australian alpaca, the 
Table 1. Average, s.d., confidence intervals, lower and upper values of monthly staple length growth rate (FLG, cm) of young alpacas by genotype, sex and month, and total annual increase in staple length.

Promedio, d.s., intervalos de confianza, valores superiores e inferiores de la tasa de crecimiento de longitud promedio (FLG, $\mathrm{cm}$ ) de alpacas jóvenes por genotipo, sexo y mes, e incremento total anual en longitud promedio.

\begin{tabular}{|c|c|c|c|c|c|c|c|}
\hline Factors & Levels & $N$ & $\begin{array}{l}\text { FLG* } \\
(\mathrm{cm})\end{array}$ & s.d. & $\begin{array}{c}95 \% \\
\text { Confidence interval }\end{array}$ & Lower & Upper \\
\hline \multirow{2}{*}{ Genotype } & Suri & 108 & $1.34^{\mathrm{a}}$ & 0.03 & $1.28-1.39$ & 0.82 & 1.60 \\
\hline & Huacaya & 156 & $1.10^{\mathrm{b}}$ & 0.01 & $1.07-1.12$ & 0.67 & 1.56 \\
\hline \multirow{2}{*}{ Sex } & Female & 120 & $1.18^{\mathrm{a}}$ & 0.02 & $1.14-1.22$ & 0.67 & 1.60 \\
\hline & Male & 144 & $1.25^{\mathrm{a}}$ & 0.02 & $1.21-1.29$ & 0.71 & 1.56 \\
\hline \multirow[t]{12}{*}{ Month } & April & 22 & $0.80^{\mathrm{a}}$ & 0.02 & $0.77-0.84$ & 0.67 & 1.02 \\
\hline & May & 22 & $0.98^{\mathrm{b}}$ & 0.03 & $0.92-1.04$ & 0.75 & 1.17 \\
\hline & June & 22 & $1.31^{\mathrm{cd}}$ & 0.02 & $1.26-1.36$ & 0.89 & 1.56 \\
\hline & July & 22 & $1.25^{\mathrm{cd}}$ & 0.04 & $1.18-1.33$ & 1.03 & 1.45 \\
\hline & August & 22 & $1.32^{\mathrm{d}}$ & 0.03 & $1.26-1.39$ & 1.00 & 1.45 \\
\hline & September & 22 & $1.14^{\mathrm{cd}}$ & 0.03 & $1.07-1.20$ & 0.89 & 1.30 \\
\hline & October & 22 & $1.34^{\mathrm{d}}$ & 0.03 & $1.27-1.41$ & 1.07 & 1.50 \\
\hline & November & 22 & $1.34^{\mathrm{d}}$ & 0.05 & $1.24-1.43$ & 0.97 & 1.50 \\
\hline & December & 22 & $1.17^{\mathrm{bc}}$ & 0.03 & $1.06-1.17$ & 0.86 & 1.22 \\
\hline & January & 22 & $1.34^{\mathrm{d}}$ & 0.05 & $1.24-1.43$ & 0.97 & 1.50 \\
\hline & February & 22 & $1.22^{\mathrm{cd}}$ & 0.02 & $1.18-1.26$ & 0.97 & 1.41 \\
\hline & March & 22 & $1.4^{\mathrm{d}}$ & 0.03 & $1.36-1.46$ & 1.10 & 1.60 \\
\hline \multicolumn{2}{|l|}{ Mean/month } & 22 & 1.13 & 0.02 & $1.08-1.17$ & 0.98 & 1.36 \\
\hline \multicolumn{2}{|c|}{ Annual increase in staple length } & 22 & 13.53 & 0.25 & $13.0-14.1$ & 11.8 & 16.3 \\
\hline
\end{tabular}

* Average. Different letters for each factor show statistical differences with confidence level of $95 \%$.

SL of Suri alpaca was $3.2 \mathrm{~cm}$ longer than Huacaya alpaca (McGregor 2006).

The apparent difference in fiber length between Suri and Huacaya alpaca may be related to the natural fiber curvature or fiber crimp frequency, which is greater in Huacaya than with Suri alpaca (McGregor 2006). It has been shown in Merino wools that the actual straight length of a fiber depends on its crimp form and frequency, with helically crimped fibers being longer than fibers with sinusoidal crimp, given the same initial crimped length (Balasubramaniam and Whitely 1964). They derived equations for estimating the straight length of wool fibers for different wave forms. Therefore, to define the differences between alpaca breeds it is required the measurement of fiber length when stretched under a standard load. Another way of evaluating fiber length would be to evaluate FLG under the premise that a reduced FLG is correlated with a reduction of fiber diameter (Brown and Crook 2005, Smith et al 2006, Franco et al 2009).
The result that the sexes had the same FLG indicates that young growing males and females grazed in the same environment do not differ in their FLG, as they most likely have similar nutrition and live weight as previously observed (McGregor 2006).

The progressive increase in SL may allow the shearing of alpaca at eight months of age, because the cumulative length obtained of about $9 \mathrm{~cm}$ is sufficient for textile processing. However, shearing at 12 months of age will provide sufficient length for worsted processing at near $14 \mathrm{~cm}$. Thus alpacas born in the calving season between January and March can be sheared at the end of the same year and produce fiber of sufficient length for textile processing.

We conclude that under grazing conditions in the High Andes in Peru, the fibers covering young alpacas increased in length growth rate over each of the first three months and then maintained a near constant increase in length growth for the remainder of their first year. Suri alpaca grew longer staples than Huacaya alpaca. There 

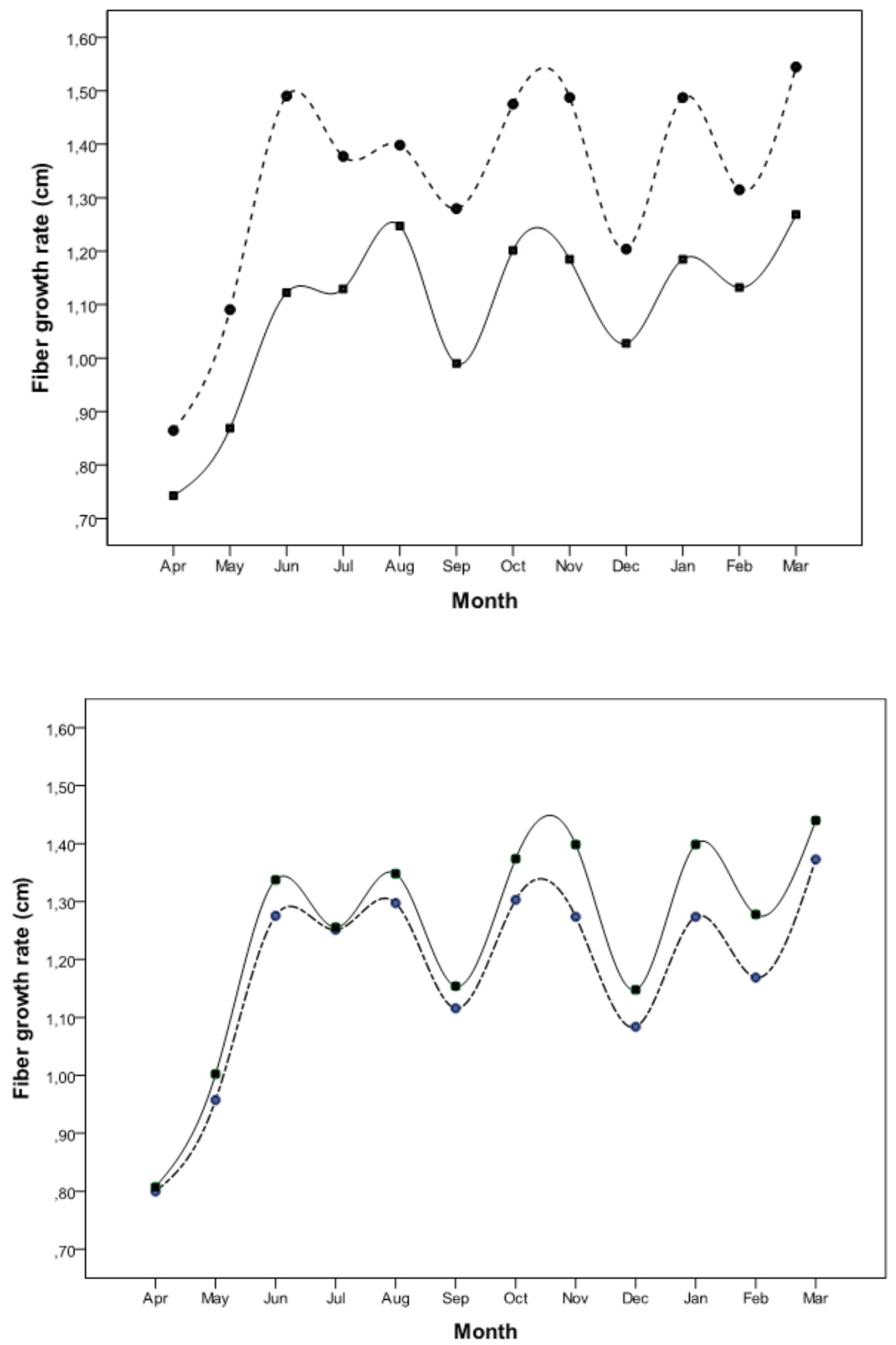

Figure 1. Staple length growth rate profile by genotype (upper, Suri $\cdots$, Huacaya - ) and sex (lower, female $\cdots$, male - ) throughout the first year of life (from April 2010 to March 2011).

Perfil de la tasa de crecimiento de longitud promedio (superior, Suri $\cdots$, Huacaya - ) y sexo (inferior, hembra $\cdots$, macho - ) durante el primer año de vida (desde abril 2010 a March 2011). 
was no effect of sex on staple length growth. The resulting staple length indicates that shearing at ages from 8 to 12 months of age will provide fleeces of sufficient length for textile processing.

\section{REFERENCES}

Balasubramaniam E, KJ Whitely. 1964. Theoretical configurations of single wool fibres 1 . Sine and helical forms. Aust J Appl Sci 15, 41-52.

Brown DJ, BJ Crook. 2005. Environmental responsiveness of fibre diameter in grazing fine wool Merino Sheep. Aust $J$ Agric Res 56, 673-684.

Carpio M. 1991. Aspectos tecnológicos de la fibra de camélidos sudamericanos. En: Novoa C, Flores A (eds). Producción de ruminates menores: Alpacas. Imprenta Rerumen, Lima, Perú. Pp 297-359.

Chapman R, JL Wheeler. 1963. Dye-banding: A technique for fleece growth studies. Aust J Sci 26, 53-54.

Franco F, F San Martin, M Ara, L Olazábal, F Carcelén. 2009. Efecto del nivel nutricional sobre el rendimiento y calidad de la fibra de alpaca. Rev Inv Vet Peru 20, 187-195.

Lupton CJ, A McColl, RH Stobart. 2006. Fiber characteristics of the Huacaya Alpaca. Small Rumin Res 64, 211-224.

Mayhua P, EC Quispe, M Montes, L Alfonso. 2011. Differences in fibre diameter profile between shearing periods in White Huacaya Alpacas (Vicugna pacos). In: PérezCabal MA, Gutiérrez JP, Cervantes I, Alcalde MJ (eds). Fibre production in South American camelids and other fibre animals, Wageningen Academic Publishers, Netherlands, Pp 59-64.

McGregor BA. 2002. Comparative productivity and grazing behaviour of Huacaya alpacas and Peppin Merino sheep grazed on annual pastures. Small Rumin Res 44, 219-232.

McGregor BA. 2006. Production, attributes and relative value of alpaca fleeces in southern Australia and implications for industry development. Small Rumin Res 61, 93-111.

McGregor BA, KL Butler. 2004. Sources of variation in fibre diameter attributes of Australian alpacas and implications for fleece evaluation and animal selection. Aust J Agric Res 55, 433-442.

Poma AG, CF Ventura, EC Quispe. 2009. Caracterización del perfil de diámetro de fibra en alpacas Huacaya de color blanco. Thesis, Universidad Nacional de Huancavelica, Huancavelica, Perú.

Quispe EC. 2011. Estimación de la respuesta a la selección bajo seis esquemas de selección de alpacas Huacaya (Vicugna pacos 1.) con tres modelos de evaluación en la región alto andina de Huancavelica. PhD Thesis. Universidad Nacional Agraria La Molina, Lima, Perú.

Quispe EC, L Alfonso, A Flores, H Guillén. 2009ª Bases para un programa de mejoramiento genetic de alpacas en la zona alto andina de Huancavelica - Perú. Arch Zoot 58, 705-716.

Quispe EC, TC Rodríguez, LR Iñiguez, JP Mueller. 2009 . Fiber Production of alpaca, llama, vicuña and guanaco in South America. Anim Genet Res Inform 45, 1-14.

Smith J, IW Purvis, GJ Lee. 2006. Fibre diameter profiles - potential applications for improving fine-wool quality. Internat J Sheep Wool Sci 54, 54-61.

Sohie MS. 2003. Analytical techniques for differentiating Huacaya and Suri Alpaca Fibers. PhD Thesis. Textiles and Clothing Graduate Program, Ohio State University, Ohio, USA.

Solis RH. 2000. Producción de Camélidos Sudamericanos. $2^{\mathrm{a}}$ ed. Cerro de Pasco, Perú..

Villarroel J. 1959. A study of alpaca fibre. MSc Thesis. School of Wool, University of New South Wales, Sydney, Australia.

Watkins P, A Buxton. 1992. Luxury Fibres. The Economist Intelligence Unit Special Report No. 2633. Business International, London, UK.

Wang X, L Wang, X Liu. 2003. The Quality and Processing Performance of Alpaca Fibres.. RIRDC Publication No 03/128. Rural Industries Research and Development Corporation, Melbourne, Australia.

Wuliji T, GH Davis, KG Dodds, PR Turner, RN Andrews, GD Bruce. 2000. Production performance, repeatability and heritability estimates for live weight, fleece weight and fiber characteristics of alpacas in New Zealand. Small Rumin Res 37, 189-201. 
